\title{
e-HR and Employee Self Service: A Case Study of a Victorian Public Sector Organisation
}

\author{
Paul Hawking and Andrew Stein \\ Victoria University, Melbourne, \\ Victoria, Australia
}

\author{
Paul.Hawking@vu.edu.au \\ Andrew.stein@vu.edu.au
}

\author{
Susan Foster \\ Monash University, \\ Victoria, Australia
}

Sue.foster@sims.monash.edu.au

\begin{abstract}
The application of the internet to the Human Resource function (e-HR) combines two elements: one is the use of electronic media whilst the other is the active participation of employees in the process. These two elements drive the technology that helps organisations lower administration costs, improve employee communication and satisfaction, provide real time access to information while at the same time reducing processing time. This technology holds out the promise of challenging the past role of $\mathrm{HR}$ as one of payroll processing and manual administrative processes to one where cost efficiencies can be gained, enabling more time and energy to be devoted to strategic business issues. The relative quick gains with low associated risk have prompted many Australian companies to realise what can be achieved through the implementation of a business to employee (B2E) model. Employee Self Service (ESS), a solution based on the B2E model enables employees to access the corporate human resource information system $24 \times 7$. This paper adopts a case study approach with a view to investigating the benefits and associated issues obtained from an implementation of an ESS in an Australian public sector organisation.Keywords: Employee Self Service, e-Human Resources, B2E, HRMIS, ERP Systems, Australian Case Study

\section{Introduction}

The Human Resource Management (HRM) function has changed dramatically over time evolving from the traditional administrative function primarily responsible for payroll processing to a more strategic direction of human capital management that can add value to an organization (Malis, 1998; Walker, 2001). As companies now realise the importance of this function they are investing resources into supporting Human Resource Management Information Systems (HRMIS).

Using information systems to support HR functions is not a new concept but as the focus of HRM has evolved, so has the IS systems that support it. Companies realising the important strategic nature of HRM, are bolting on HRIS modules to their current Enterprise Resource Planning (ERP) systems. These are integrated information systems, supporting various business processes

Material published as part of this journal, either on-line or in print, is copyrighted by Informing Science. Permission to make digital or paper copy of part or all of these works for personal or classroom use is granted without fee provided that the copies are not made or distributed for profit or commercial advantage AND that copies 1) bear this notice in full and 2) give the full citation on the first page. It is permissible to abstract these works so long as credit is given. To copy in all other cases or to republish or to post on a server or to redistribute to lists requires specific permission from the publisher at Publisher@InformingScience.org in different functional areas across the organization and are considered essential infrastructure by some of the world's leading companies. Over the last decade sales of these systems are estimated to be worth US $\$ 300$ billion (Carlino, 2000). ERP systems being modular in nature allow companies the flexibility to implement relevant
\end{abstract}


modules depending upon which business processes they want supported. The leading vendor with approximately $54 \%$ of the market is SAP (McBride, 2003). Initially ERP systems were implemented to provide a number of advantages; integration of business processes in such areas as financials, materials management, production planning, and sales and distribution (Curran \& Kellar, 1998), a common platform, better data visibility, lower operating costs, increased customer responsiveness and improved strategic decision making (Iggulden, 1999). However as companies are realising the importance of HRM they are implementing the appropriate ERP modules to support this function. This trend is reflected in companies in Australian and New Zealand. Of the 400 companies that have implemented SAP's, ERP system, 190 have implemented its HR functionality (McBride, 2003). To achieve strategic value from an HRMIS reinforces the fact that they can no longer exist in isolation from other business processes within a company. This fact, together with the added costs of system interfaces, is usually a deterrent for stand alone HRM systems.

\section{Evolution of HR - Web-based Applications}

As HR has evolved, the level of associated administrative duties has increased proportionally with some research estimating that as much as $70 \%$ of HR personnel time is spent on administrative duties (Barron, 2002). This has been estimated to represent a cost of up to \$US1700 per employee per year (Khirallah, 2000). It has been further estimated (Wagner, 2002) that HR paper forms cost \$20-\$30 to process, telephone based HR forms cost \$2-\$4 to process but Internet based HR forms cost only 5-10 cents. In an attempt to exploit these cost differences companies have looked to the Internet for the solution.

Initially employees were only able to view and browse electronic versions of existing corporate documents. But as familiarity increased in the use of on-line technology and with the increasing maturity of network and browser technology, applications have evolved to incorporate transactional interactions. As such companies have been transferring more and more of their corporate information resources to web based applications, making them readily accessible to employees via the corporate intranet. A survey by Watson Wyatt (B2E / e-HR European Survey Results 2002) indicates that although a large proportion of companies have introduced static e-HR capabilities, the use of interactive e-HR is increasing rapidly. Findings indicate that $80 \%$ of its surveyed respondents are looking to introduce or add to existing interactive capabilities and that $75 \%$ of companies are looking to make changes to their e-HR capabilities over the next 2 years. This finding supports recent research into 500 companies in the UK conducted by Microsoft Great Plains Business Solutions which reveals that $30 \%$ of UK companies now rank e-HR as their

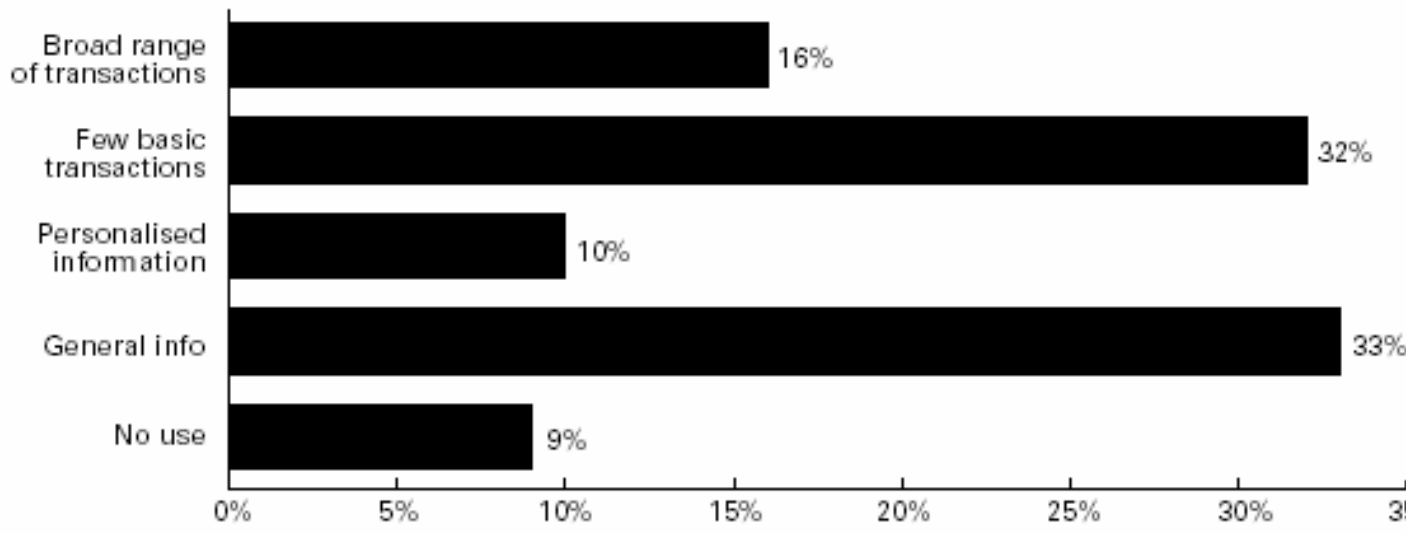

Source: Towers Perrin e-Track: web-based self-service: The current state of the art

Figure 1. Indicates the outcomes from companies who use static information 
number one business e-initiative. Although the majority of B2E solutions were still considered to be at a basic level, focussing on improved efficiency and electronic document delivery (Dunford, 2002).

More detailed research by Towers Perrin indicates that companies who have made their sites interactive are reporting greater overall successes compared to those that have limited themselves to static information (see Figure 1).

These successes come in the form of improved service to employers and managers (98\%) increased information access $(90 \%)$, reduction in administrative costs $(85 \%)$ and processing time (70\%) with the added benefit of enabling HR to concentrate on more tactical and strategic issues (80\%). These benefits (see Figure 2) indicate the inherent value that can be gleaned from introducing an e-HR initiative (Ministry of ManPower, 2003).

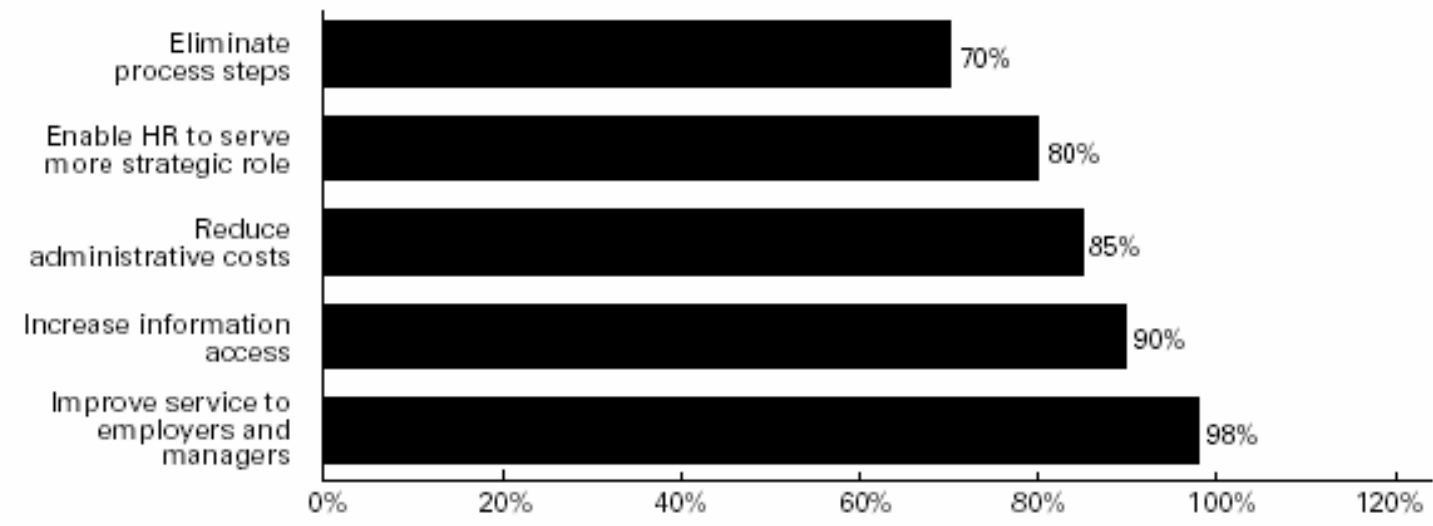

Source: Cedar 2001 Human Resources Self Service/Portal Survey

\section{Figure 2. Illustrates the five main objectives that are reported by companies introducing e-HR initiatives}

One of the many web based applications to support HRM is Employee Relationship Management (ERM). Hamerman (2002) considers ERM suites as an evolution of self-service technology to support managers and employees, providing the platforms for information delivery, process execution and collaboration in the organisation. The advantages in empowering employees through an ERM suite include: multiple value propositions, consistent portal GUIs, all employee 24x7, real-time dynamic information delivery and a comprehensive collaborative work environment. Employees can now access a range of information pertinent to themselves without relying on others. For example: They can compare pay slips for a number of given periods; view their superannuation and leave entitlements as well as being able to apply for leave online. These suites offer a multiple relationship dimension through the use of multiple applications.

Employee Relationship Management (ERM) landscape is displayed reflecting the interrelatedness between corporate, personal and employee elements (Hamerman, 2002). (See Figure 3.) 


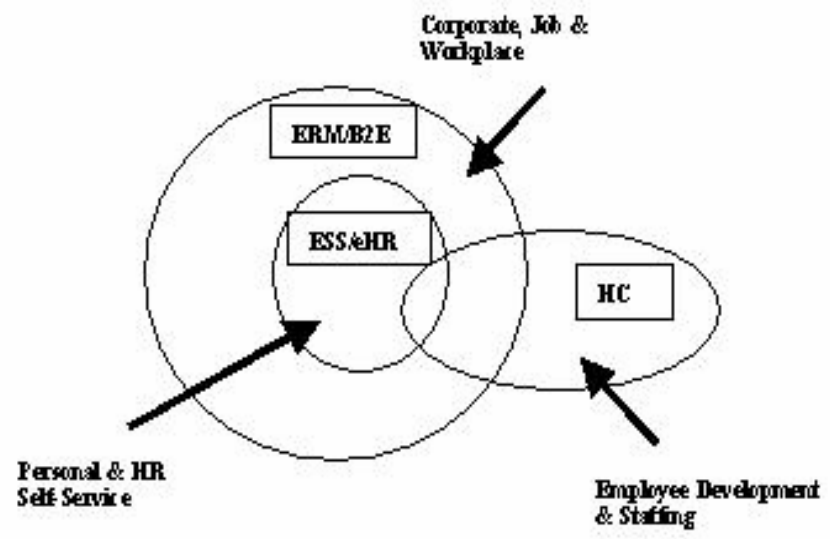

Figure 3. The Employee Relationship Management Landscape (Hamerman, 2002)

As can be seen from the adoption trends (Figure 4) between 1998 to the forecasted 2006, the percentage uptake of some of the main ERM applications are growing exponentially with the top growth taken up by Employee Self Service (ESS) (70\%) followed by employee portals (68\%), and Manager self-service (65\%).

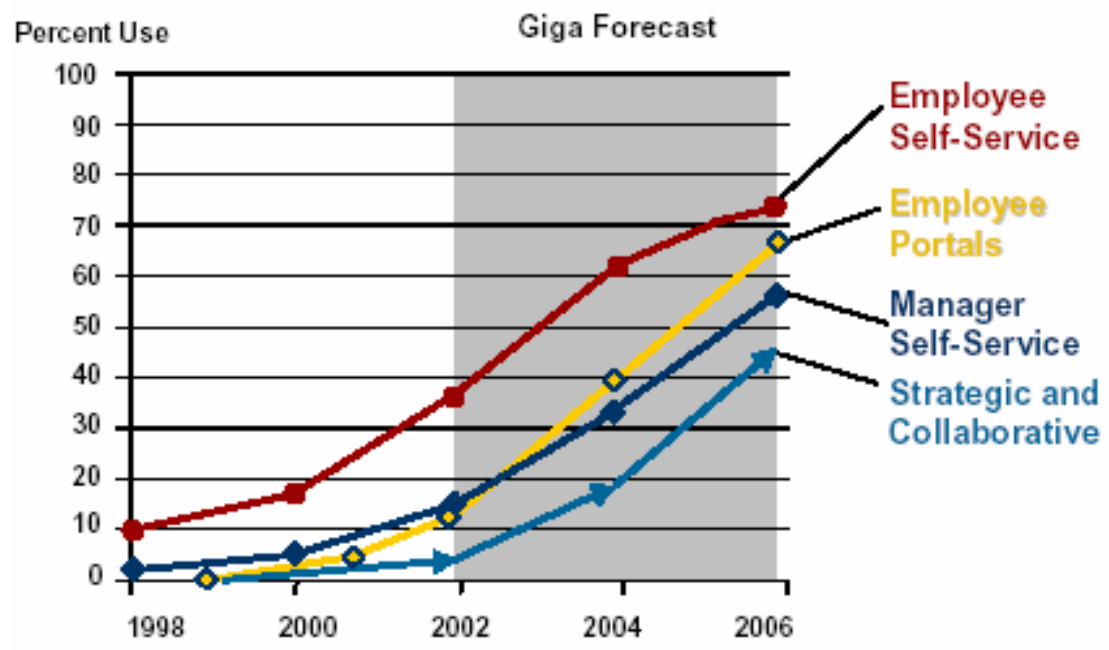

Figure 4. Adoption trends: ERM Applications (Hamerman, 2002)

\section{Employee Self Service (ESS)}

The influence of internet and browser technology has seen the growth of Employee Self Service (ESS) implementations. ESS is an Internet based solution providing employees with a browser interface to relevant HR data and transactions, enabling real time access to their data without leaving their desktop. Employees are able to: update their personal details, apply for leave, view their pay details and associated benefits, view internal job vacancies and book training and travel.

The tangible and intangible benefits of ESS solutions have been well documented (Alexander, 2002; McKenna, 2002; Webster \& Buchanan, 2002; Wiscombe, 2001) and include reduced administrative overheads, freeing up HR staff for more strategic activities, improved data integrity, and empowerment of employees. One report identified a major benefit as the provision of HR services to employees in a geographically decentralised company (NetKey, 2002). Other tangible 
measures include reductions in administrative staff by $40 \%$, reductions in transaction costs of up to $50 \%$ (Wiscombe, 2001) and the reduction in processing activities from several days to a few hours (NetKey, 2002). Ordonez (2002) maintains the theme of information delivery in presenting ESS as allowing employees access to the right information at the right time to carry out and process transactions. ESS further provides the ability to create, view and maintain data through multiple access technologies. Companies such as Toyota Australia are extending this functionality beyond the desktop by providing access to electronic HR Kiosks in common meeting areas. In Australia approximately 50 companies have implemented SAP's ESS functionality: including, Westpac, RMIT, National Australia Bank, Siemens, Telstra, and Linfox.

\section{e-Commerce: Business to Employee (B2E)}

In recent times there has been a plethora of research associated with the impact and implications of e-commerce. Much of this research has focused on the various business models such as business-to-business and business-to-consumer with the importance of developing customer and partner relationships being espoused. But little attention has been paid to the potential of business to employee (B2E) and the role that B2E systems can play in improving business to employee relationships.

The Cedar group (Cedar Group, 1999, 2000, 2001, 2002) carry out extensive annual surveys of major global organisations and their B2E intentions. Their research covers many facets of ESS; including technology, vendors, drivers, costs and benefits. Their findings indicate the average expenditure in 2001 on an ESS implementation was \$US1.505 million (see Figure 5).

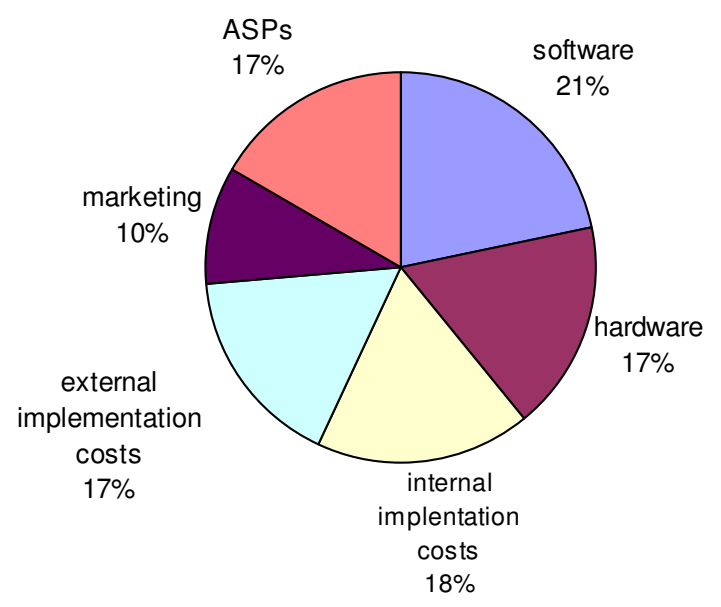

Figure 5. Average \% breakdown on ESS implementation

Viewing this cost from an employee perspective, the average cost of ESS implementation ranges from \$US32/employee for a large organisation ( $>60,000$ employees) to \$US155/employee for a medium size organisation (7,500 employees).

The main drivers for ESS have been identified as: improved service (98\%), better information access $(90 \%)$, reduced costs $(85 \%)$, streamlined processes $(70 \%)$ and strategic HR $(80 \%)$. A variety of applications are used by employees but the main applications were employee communications $(95 \%)$, pension services (72\%), training (40\%), and leave requests $(25 \%)$. Interestingly, managers in the three regions of the survey use Managers self-service (MSS) differently: North American managers use MSS to process travel and expenses claims, (42\%), European managers process purchase orders (48\%) and Australian managers process leave requests (45\%). 
Employee services can be delivered by a variety of methods and web-based self-service (B2E) is undergoing substantial planned growth from $42 \%$ in 2001 to $80 \%$ planned in 2004 (Cedar group, 2002). The trend is for implementing HRMIS applications from major vendors like SAP or PeopleSoft. ESS implementations show overwhelming success measures with 53\% indicating their implementation was successful and $43 \%$ somewhat successful. The value proposition for ESS includes:

- Average cost of transaction (down 60\%),

- Inquiries (down 10\%),

- Cycle time (reduced 60\%),

- Headcount (70\% reduction),

- R.O.I. (100\% in 22 months) and

- Employee satisfaction (increased 50\%).

The culmination of the Cedar group (2002) report lists the barriers to benefit attainment and critical success factors in ESS applications. North American and Australian organisations both list cost of ownership/lack of budget as the main barriers, whilst European organisations perceive lack of privacy and security as the main barriers. Other barriers include; lack of technical skills, inability to state business case, low HR priority and HRMS not in place. As with other complex IT application projects, executive commitment, internal collaboration and availability of technical skills to implement the application are considered important success factors.

With the claim by ESS solutions to incorporate "best business practice", and with the return on investment that ESS renders (Lehman, 2000), it is understandable that there has been a significant growth in companies implementing ESS solutions (Webster Buchanan, 2002). However to date there has been little documented about how Australian companies are utilising ESS solutions and associated issues.

\section{Research}

To further investigate the issues involved in implementing and using this type of solution and to validate recent findings as discussed in the literature review, a case study approach was adopted. This case study was designed to investigate and describe the added value and benefits to employees of this type of functionality and discuss issues involved in implementing an Employee Self Service within a public sector organisation. Case study research is considered a valid technique when investigating information systems usage and implementation. Yin (1994) believes the importance of asking "what" type questions when analysing information systems is best achieved via this type of research (p. 35). Walsham (2000) also supports case study methodology and sees the need for a move away from traditional information systems research methods such as surveys towards more interpretative case studies, ethnographies and action research projects (p.204). Several works have used case studies (Chan \& Roseman, 2001; Lee, 1989) in presenting information systems research. Cavaye (1995) used case study research to analyse inter-organisational systems and the complexity of information systems.

This case study was developed from initial interviews conducted with the key managers of the organisation. Predetermined questions formed the basis of the interviews and these were supported by observations through access to the ESS systems. Interviews were transcribed and clarification of points and follow up queries were conducted via email and telephone. Project documentation and policy documents were made availability. Confidentiality guidelines were adhered to in the presentation of findings. 
Hawking, Stein, \& Foster

\section{Case Study: Public Sector Organisation}

The organisation employs approximately 5,000 staff at more than 180 diverse locations across Victoria. Prior to 1999, the department had been using its own "in house" developed HR system (HRSYS) for 8 years which included a limited ESS which did not incorporate browser technology. Although few complaints had been reported in regards to this system, due to a restructure within the state government in early 1998, a number of departments were amalgamated forming the current department, resulting in nine different HR/Payroll systems being used. Due to incompatibility issues and Y2K, it was decided to implement SAP's HR/Payroll module (4.0b) which included the ESS module and SAPs Workflow tool to replace the current systems. (Workflow automates many business processes. Once a particular event has occurred, documents are initiated and sent out to the appropriate personnel.)

After seven months of implementation the system went live in June 1999. The ESS system was implemented in all of the department's eight geographical sites across the state and supported 95\% of the employees. In most regions employees connected to the ESS via the Department's network backbone, resulting in a response time of less than one second. In a few remote locations employees had to rely on dial up internet connection to access the ESS and therefore response times were slower (1-2 minutes). In some remote regions ESS Kiosks had been installed to allow access. The Kiosks are PC's based in common areas usually supporting up to 20 employees. In terms of security, each employee is supplied with a username and password, with the password requiring to be changed every 90 days. However the maintenance of passwords has become a big support issue, as employees fail to remember the passwords. Several other security strategies have been introduced to limit access to information by unauthorised personnel. One such security measure has been implemented in SAP ESS, if an employee stops using their screen for three continuous minutes the system automatically logs the user out, preventing other staff members viewing and changing personnel data.

The ESS system allows employees a broad range of functionality. In terms of Employee Details, employees could view and edit basic information about themselves online; changing their home, mailing, and work addresses as well as maintaining their emergency contact details. A number of details were able to be viewed but not edited including educational qualifications, skills and competencies, bank details, superannuation and taxation details. If any of these details were incorrect or needed to be changed employees were required to submit authorised documentation to their supervisor for verification which was then forwarded to the HR department.

The system also allows employees to view their current leave balances and leave history and apply for a broad range of leave. Firstly, they identify the type of leave they are applying for from a specified list and then indicate the start and end dates of the leave. A similar process is used when applying for overtime hours except other than start and end dates being required to be included, times are also recorded. Once leave and overtime applications have been saved, an email is sent via workflow to the appropriate supervisor indicating that a request has been submitted. Supervisors can then view the requests within the ESS and either approve or reject the application.

Employees can also use the ESS system to book training courses. This is accomplished through the training calendar. To do this the employee views the training calendar and the range of available training courses; once a particular course has been chosen the employee can determine whether a vacancy exists and then initiate a booking. Again an email is forwarded via workflow to the immediate supervisor, indicating that an application has been received and is awaiting their approval. The email contains a hyperlink to the application within the SAP ESS system. Each application has buttons which enable the supervisor to approve or disapprove the application. They also have the added functionality to incorporate an attachment with the approval email to include any reasons or to request further information. Once the application has been dealt with, it 
is automatically removed from the workflow inbox. Each application has "latest end" date automatically recorded when the application is generated. If the supervisor has not processed the application by the "latest end" date then the application is escalated and an email with the details is sent to the next highest supervisor to process.

\section{Department Benefits}

The implementation of SAP's ESS has provided the Department with a number of tangible benefits. Firstly, there has been a reduction in HR/payroll processing. For example, a recent event which required the calculation of 15 months' back pay including three pay increases for 4000 employees, required only five staff, and took five days to complete with a $99.7 \%$ accuracy. A comparison estimate between the new system and the previous system, revealed that it would take twenty staff, five days with a 78\% accuracy rate. Obvious benefits included: reduction in labour, faster processing, with a significant increase in accuracy leading to increased employee satisfaction. Significant savings have also been identified with the introduction of online payslips. Overall the department believe that they have achieved $80 \%$ improvement in productivity. Intangible benefits include the integrity of employee data and the empowerment of employees to access to their own information in a timely and accurate fashion.

Although a number of benefits have been identified with this implementation there were invariably a number of issues associated with its use. Many of which can be attributed to inadequate change management strategies. Many of the employees which had used the "in house" HR system prior to the amalgamation, initially considered the original system to be more user friendly and include better reporting functionality than SAP's HR system. For example, once the new system was implemented employees could only apply for leave and overtime online forcing compliance, resulting in some initial resistance. As part of the change management process the department conducted over 200 training sessions at 80 of the 180 sites across the state. At the completion of each 45 minute training module, employees were assessed before they proceeded onto the next module. All training documents and results were recorded within the SAP HR system to support future career advancements. On completion of training it is estimated that approximately $80 \%$ of employees accepted the new system. However after 3 years of use a number of managers still believe that the previous system was better. One reason for this was that the previous system incorporated language pertinent to the department.

Additionally the ESS system changed the role of managers forcing them to use the system as part of their everyday task. This became a problem in the initial configuration of the system, and now if an employee submits an application and the manager is away, the record becomes locked and inaccessible to anyone but the manager.

\section{Conclusion}

The Aberdeen Group (2001) conclude that human capital management and HR systems have been intricately connected with the bottom line in organisations and as such have not been exploited for strategic advantage. It has been estimated that only $20 \%$ of HCM effort is spent on strategic activities. The opportunity to use the HCM and eHR systems to provide employees with more efficient means of communication, yields strategic benefits for the organisation. Recruiting, retaining and better fitting the employee to work roles and changing work patterns, are all strategic when one considers the importance of the human resource in today's information economy. This paper describes and identifies some of the benefits and issues associated with the usage of SAP's Employee Self Service, a B2E solution for HR. It emphasises the numerous gains that can be achieved by a public sector organisation, while stressing the importance of appropriate change management strategies. For this organisation the move to B2E and ESS has reduced complexity and improved focus, increased ROI and improved operational effectiveness. The employee views 
the ESS as improving work and life balance and allowing better access to information for better decision-making.

There are many terms used to describe the move from traditional HR to the "e-enabled" versions of HR; HRMIS, eHR, B2E, ESS, web enabled ESS, HR portal, ESS portal and several others. What is not fully known or understood is that these are information delivery platforms that have much potential to deliver not only cost focussed savings but the more important strategic HR benefits now being sought by modern organisations.

\section{References}

Aberdeen Group. (2001). HCM: Strategic partner, trusted adviser? April 2001.

Alexander, S. (2002). HR e-power to the people. Retrieved August 2002 from http://staging.infoworld.com/articles/ca/xml/01/02/010212cahr.xml

Barron, M. (2002). Retail web-based self-serve isn't just for customers, it's for employees. Internet Retailer. Retrieved September 2002 from http://www.internetretailer.com/dailynews.asp?id=6688

Carlino, J. (2000). AMR research predicts enterprise application market will reach \$78 Billion by 2004. Retrieved August 2002 from www.amrresearch.com/press/files/

Cavaye, A. (1996). Case study research: a multi-faceted approach for IS. Information Systems Journal, 63, 227-242.

Cedar Group. (2002). Cedar 2002 human resources self servicelportal survey. Baltimore, USA.

Cedar Group. (2001). Cedar 2001 human resources self servicelportal survey. Baltimore, USA.

Cedar Group. (2000). Cedar 2000 human resources self service. Baltimore, USA.

Cedar Group. (1999). Cedar 1999 human resources self service. Baltimore, USA.

Chan, R. \& Roseman, M. (2001). Integrating knowledge into process models - A case study. Proceedings of the Twelfth Australasian Conference on Information Systems. Australia: Southern Cross University.

Curran, T. \& Kellar, G. (1998). SAP R/3 business blueprint. New Jersey: Prentice Hall.

Dunford, I. (2002). B2E: The future looks rosy. Retrieved March 2003 from http://www.computing.co.uk/Analysis/1136393

Hamerman, P. (2002). Extending employee relationships with web applications. Presentation to SAPPHIRE Lisbon Conference, July 2002.

Iggulden, T. (Editor). (1999). Looking for payback. MIS, June, 75-80.

Khirallah, D. (2000). Picture this: self-service HR at Sony. Retrieved September 2002 from http://www.informationweek.com/811/sony.htm

Lee, A. (1989). Case studies as natural experiments. Human Relations, 422, 117-137.

Lehman, J. (2000). HR self-service strategies: Lessons learned. Gartner Research Note, September 26.

McKenna, E. (2002). Empowering employees. Retrieved August 2002 from http://www.fcw.com/fcw/articles/2002/0107/tec-hr-01-07-02.asp

Malis, E. (2002). Corporate intranets include automated time and attendance in your "HR Self Service" Offering. Crosswind. Retrieved September 2002 from http://www.crosswind.com

Ministry of Power. (2003). E-HR: Leveraging technology. Retrieved December 2003 from http://www.mom.gov.sg/MOM/LRD/Publications/2246_EHR.pdf

Netkey. (2002). Unlocking the power of HR self service. Retrieved September 2002 from www.netkey.com

Ordonez, E. (2001). MySAP human resources: Human capital management for your business. Retrieved July 2002 from http://www.sap.com 
e-HR and Employee Self Service

Wagner, M. (2002). Saving trees and serving up benefits. Internet Retailer. Retrieved June 2002 from http://www.internetretailer.com/dailynews.asp?id=6688

Walker, A. J. (2001). How the Web and other key trends are changing human resources. In A. J. Walker \& T. Perrin (Eds.), Web-based human resources. New York: R. R. Donnelley \& Sons.

Walsham, G. (2000). Globalisation and IT: agenda for research. In Organisational and Social Perspectives on Information Technology (pp. 195-210)., Boston: Kluwer Academic Publishers.

Webster Buchanan Research. (2002). HR self service - The practitioners' view. Retrieved August 2002 from www.leadersinHR.org

Wiscombe, J. (2001). Using technology to cut costs. Workforce. Retrieved September 2001 from http://www.workforce.com/archive/feature/22/29/82/index.php

Yin, R. (1994). Case study research. Design and Methods ( $2^{\text {nd }}$ edition). Newbury Park: Sage Publications.

\section{Biographies}

Paul Hawking is a senior lecturer in Information Systems in the Faculty of Business and Law at Victoria University. He is responsible for managing the university's strategic alliance with SAP and is co-ordinator of the university's ERP Research Group. He has contributed to the Journal of ERP Implementation, Journal of Contemporary Business Issues, Asia Pacific Journal of Marketing and Logistics, and presented at the $36^{\text {th }}$ HICSS in January. Paul is past Chairperson of the SAP Australian User Group and current committee member responsible for education and research.

Andrew Stein is a lecturer in the School of information Systems in the Faculty of Business and Law at Victoria University. He has contributed to numerous international journals including: International Journal of Management, Journal of Information Management, Journal of ERP Implementation and Management, Journal of Contemporary Business Issues and the Asia Pacific Journal of Marketing and Logistics and contributed to the $36^{\text {th }}$ HICSS in January. He is a member of the ERP Research Group at Victoria University.

Susan Foster is a lecturer in the School of Information Management Systems at Monash University and is a member of the ERP Research Group at Victoria University. She has contributed to the Journal of Contemporary Business Issues, Asia Pacific Journal of Marketing and Logistics and contributed to the $36^{\text {th }}$ HICSS in January. 